\title{
Prognostic significance of hemoglobin A1c level in patients hospitalized with coronary artery disease. A systematic review and meta-analysis
}

\author{
Yao Liu, Yan-min Yang ${ }^{*}$, Jun Zhu, Hui-qiong Tan, Yan Liang and Jian-dong Li
}

\begin{abstract}
Background: The prognostic value of hemoglobin A1c (HbA1c) in coronary artery disease (CAD) remains controversial. Herein, we conducted a systematic review to quantify the association between elevated HbA1c levels and all-cause mortality among patients hospitalized with CAD.

Methods: A systematic search of electronic databases (PubMed, EMBASE, OVID, Web of Science, The Cochrane Library) for studies published from 1970 to May 2011 was performed. Cohort, case-control studies, and randomized controlled trials that examined the effect of HbA1c on all-cause mortality were included.

Results: Twenty studies met final inclusion criteria (total $n=13,224)$. From the pooled analyses, elevated HbA1c level was significantly associated with increased short-term (OR 2.32, 95\% Cl, 1.61 to 3.35) and long-term (OR 1.54, $95 \% \mathrm{Cl}, 1.23$ to 1.94) mortality risk. Subgroup analyses suggested elevated HbA1c level predicted higher mortality risk in patients without diabetes (OR 1.84, 95\% Cl, 1.51 to 2.24). In contrast, in patients with diabetes, elevated $\mathrm{HbA1c}$ level was not associated with increased risk of mortality (OR 0.95, 95\% Cl, 0.70 to 1.28). In a risk-adjusted sensitivity analyses, elevated $\mathrm{HbA1c}$ was also associated with a significantly high risk of adjusted mortality in patients without diabetes (adjusted OR 1.49,95\% Cl, 1.24 to 1.79), but had a borderline effect in patients with diabetes (adjusted OR 1.05, 95\% Cl, 1.00 to 1.11).

Conclusions: Our findings demonstrate that elevated $\mathrm{HbA1c}$ level is an independent risk factor for mortality in CAD patients without diabetes, but not in patients with established diabetes. Prospective studies should further investigate whether glycemic control might improve outcomes in CAD patients without previously diagnosed diabetes.
\end{abstract}

Keywords: hemoglobin A1c, mortality, coronary artery disease, acute coronary syndrome

\section{Background}

In recent years, much attention has been paid to the glycometabolism in patients with coronary artery disease (CAD). Numerous prior studies have shown that elevated admission or fasting glucose increases the risk of death and in-hospital complications in patients with acute coronary syndrome (ACS) and patients undergoing coronary revascularization [1-5].

Hemoglobin $\mathrm{A}_{1 \mathrm{c}}\left(\mathrm{HbA}_{1 \mathrm{c}}\right)$ level is an indicator of average blood glucose concentrations over the preceding 2-3

\footnotetext{
* Correspondence: yymwin@yahoo.com.cn Institution of all authors: Emergency Department, Cardiovascular Institute and Fuwai Hospital; Chinese Academy of Medical Sciences \& Peking Union Medical College, (167 Beilishilu Road), Beijing, (100037), China
}

months, which is a convenient and well-known biomarker in clinical practice. Epidemiological evidence now suggests that HbA1c level is an independent risk factor for cardiovascular events in primary and secondary populations [6-9]. Recently, an International Expert Committee Report (IECR) recommended using the HbA1c assay as the preferred method for diabetes diagnosis and suggested the diagnosis if the HbA1c level is $\geq 6.5 \%$ [10]. However, the prognostic value of HbA1c level in patients with coronary atherosclerotic disease has not been well characterized, and these studies that examined this relationship have reported conflicting results [11-23].

\section{() BiolMed Central}

(c) 2011 Liu et al; licensee BioMed Central Ltd. This is an Open Access article distributed under the terms of the Creative Commons Attribution License (http://creativecommons.org/licenses/by/2.0), which permits unrestricted use, distribution, and reproduction in any medium, provided the original work is properly cited. 
To comprehensively analyze these data, we performed a systematic review to examine whether an association exists between elevated $\mathrm{HbA1c}$ and all-cause mortality in patients hospitalized with CAD.

\section{Methods}

The methods for this meta-analysis are in accordance with "Meta-Analysis of Observational Studies in Epidemiology: A Proposal for Reporting." [24]

\section{Search strategy}

A systematic search of publications listed in the electronic databases (Medline via PubMed, EMBASE, OVID, Web of Science, The Cochrane Library) from 1970 to May 2011 were conducted using the following key words in combination as both MeSH terms and text words: ("coronary artery disease" or "acute coronary syndrome" or "acute myocardial infarction" or "percutaneous coronary intervention" or "coronary artery bypass grafting") and ("glycated hemoglobin" or "hemoglobin A1c" or "HbA1c"). Language restrictions were not applied, but our search was limited to human studies. The list of articles was reviewed independently by two authors. In addition, a manual review of references from primary or review articles was performed to identify any additional relevant studies

\section{Study selection}

Cohort, case-control studies, and randomized controlled trials were included if they investigated the influence of HbA1c on all-cause mortality in patients admitted with CAD. The IECR recommended that $\mathrm{HbA}_{1 \mathrm{c}}$ level $>6.5 \%$ would be the cut-off value for diagnosis of diabetes [10]. In patients with diabetes, the American Diabetes Association (ADA) recommended $\mathrm{HbA}_{1 \mathrm{c}}<7 \%$ is associated with a lower risk of diabetes-associated complications [25]. We anticipated that not all studies would use HbA1c value $6.5 \%$ or $7 \%$ as the cut-off point. Therefore, in order to avoid eliminating studies with important information, we considered HbA1c cut-off within the range of $5 \%-8 \%$ to be acceptable.

After obtaining full reports of candidate studies, the same reviewers independently assessed eligibility. Differences in data between the two reviewers were resolved by reviewing corresponding articles, and the final set was agreed on by consensus. If the publications did not contain the full information necessary for meta-analysis, we obtained the missing information directly from the authors (see Acknowledgments).

\section{Quality assessment and data abstraction}

Each study was evaluated for quality according to the guidelines provided by the United States Preventive Task Force [26] and published recommendations [27].
The following characteristics were assessed: (1) description of patient sample characteristics; (2) clear inclusion and exclusion criteria; (3) potential selection bias; (4) a priori definition of study outcomes; (5) completeness of follow-up; (6) adjustment of possible confounders in multivariate analysis; (7) explanation of sample selection; and (8) timing of determination (whether HbAlc measured at baseline). Studies were graded as poor quality if they met $\leq 4$ criteria, fair if they met 5 to 6 criteria, and good if they met $\geq 7$ criteria.

For each study, the following data were extracted: first author's last name, the publication year, study design, the sample size, study population, baseline characteristics, length of follow-up, timing of HbA1c measurement, cut-off value of HbA1c, variables adjusted for in the multivariate statistical analysis, mortality data among patients with and without elevated HbA1c level, and adjusted mortality hazard ratios (HRs) with their 95\% CIs if possible.

\section{Statistical analyses}

We used REVMAN software (version 5.0; Cochrane Collaboration, Oxford, United Kingdom) and Stata software (version 11.0; Stata Corporation, College Station, TX) to pool data for all outcomes. Firstly, unadjusted short and long term all-cause mortality data were extracted and pooled to calculate odds ratio (OR) and 95\% CI using a random effects model for dichotomous outcomes. Relative risks were also calculated separately for diabetic and non-diabetic patients when possible. Secondly, we performed baseline risk-adjusted analyses to determine if our main results were robust when quantitative pooling was limited to those studies in which we could calculate pooled adjusted all-cause mortality ORs. Heterogeneity was assessed visually using Cochran's $\chi^{2}$ statistics and the $\mathrm{I}^{2}$ statistics. A randomeffect model of DerSimonian and Laird was applied to calculate overall differences. Publication bias was estimated using a funnel plot of study results against study precision. We tested symmetry of the funnel plot using the Egger's test. P value was considered statistically significant at $<0.05$.

\section{Results}

Study selection

Our initial search yielded 1883 potential literature citations. Of these, 1844 were excluded after scanning titles and abstracts, leaving 39 citations for full text assessment. Of these, 20 studies with a total of 13, 224 patients met the inclusion criteria and were used for this meta-analysis [13-23,28-36]. The remaining studies were excluded largely because they did not include mortality as an outcome or did not provide mortality data according to $\mathrm{HbA1c}$ level; other subjects were included 
besides CAD patients; or reported $\mathrm{HbA1c}$ was in an unusable format (mean and SDs for patients with and without mortality). Additional data were requested from the authors of three studies $[11,12,19]$ but obtained for only one study [19].

\section{Characteristics of the trials}

Baseline characteristics of the 20 studies included are shown in Additional file 1 and six studies were retrospective $[19,22,28,32,33,36]$. We found no randomized controlled trial that examined the effect of HbA1c on mortality in patients admitted with CAD. Demographic features of study populations (age, gender) were similar across the studies, and the average age of the patients ranged from 56 to 75 years. The study population included 5258 patients (40\%) admitted with AMI or ACS, 4948 (37.4\%) patients who underwent CAGB and 2990 patients (22.6\%) underwent PCI. Five of the 20 studies investigated short-term (less than 3 months) allcause mortality [28-30,34,36], 13 studies reported longterm ( 1 year to 8 years) mortality [13-20,22,23,32,33,35] and 2 studies with both short and long-term follow-up results [21,31]. All studies were of high methodological quality (good or fair) (Additional file 1).

Table 1 shows baseline characteristics and treatment of the patients in original articles according to HbA1c level. As expected, patients with elevated HbA1c level had a higher prevalence of comorbidities including hypertension, heart failure, previous $\mathrm{MI}$ and renal insufficiency. Use of angiotensin-converting enzyme (ACE) inhibitors, $\beta$-blockers and lipid lowering drugs was higher in patients with elevated HbA1c compared to those with normal HbA1c level.

Six studies [13,16,18,21,22,28] exclusively examined non-diabetic patients, and the other six studies studied diabetes alone $[14,15,32,33,35,36]$, the percent of diabetic patients was not reported in two studies $[19,30]$ and the rest incorporated patients with and without diabetes $[17,20,23,29,31,34]$. Diabetes status was assigned on the basis of a history of diabetes or treatment with hypoglycemic agents in 10 studies $[14,15,17,20,23,29$, $31,32,34,35]$; in three of these studies, an elevated HbA1c [35] or plasma glucose [14,17,35] was also used to define newly diagnosed diabetes for patients without diabetes history. The definition of diabetes was not specified in two studies [33,36].

\section{$\mathrm{HbA1c}$ and risk of mortality}

Nineteen studies reported all-cause mortality data according to HbA1c levels [13,15-23,28-36] (Figure 1). Analyses of the crude mortality revealed that $14.1 \%$ of patients with elevated $\mathrm{HbA1c}$ level died compared with $11.7 \%$ of those with normal HbA1c. This translated into an unadjusted mortality risk of OR 1.68 (95\% CI, 1.38 to 2.06) in patients with elevated HbA1c. There was moderate statistical heterogeneity among the studies $\left(\mathrm{I}^{2}=\right.$ $49 \%, \mathrm{p}<0.001)$. We found no evidence of publication bias based on funnel plot or using the Egger's test $(\mathrm{P}=$ 0.089). Subgroup analyses showed in the short-term follow up cohort, the elevated HbA1c level was associated with a more than two-fold increased risk of mortality (OR 2.32, 95\% CI, 1.61 to 3.35), with no evidence for overall heterogeneity $\left(\mathrm{I}^{2}=0 \%, \mathrm{p}=0.48\right)$. Whereas patients with higher HbA1c level had a $54 \%$ increased risk of long-term mortality (OR 1.54, 95\% CI, 1.23 to 1.94). And there was no significant difference between the short-term and long-term results $(\mathrm{p}=0.06$ for subgroup difference).

In addition, we performed a subgroup analyses to compare the association between HbA1c and mortality in patients with and without diabetes. These analyses were restricted to the 12 studies in which separate mortality

Table 1 Baseline characteristics of the study population according to HbA1c

\begin{tabular}{|c|c|c|}
\hline Baseline Characteristics & Patients With Elevated $\mathrm{HbA} 1 \mathrm{c}$ & Patients With Normal HbA1c \\
\hline Age $(y)$, studies $=12, n=10734$ & 64 & 65 \\
\hline Male $(\%)$, studies $=12, n=10734$ & 64 & 72 \\
\hline $\begin{array}{l}\text { History of Hypertension (\%), } \\
\text { studies }=10, \mathrm{n}=10242\end{array}$ & 74 & 59 \\
\hline $\begin{array}{l}\text { History of Heart failure (\%), } \\
\text { studies }=4, n=5276\end{array}$ & 22 & 14 \\
\hline Previous MI (\%), studies $=3, \mathrm{n}=4219$ & 48 & 24 \\
\hline Hyperlipidemia (\%), studies $=3, n=4149$ & 36 & 35 \\
\hline Smoker (\%), studies $=7, \mathrm{n}=3770$ & 40 & 41 \\
\hline Body mass index $(\mathrm{kg} / \mathrm{m} 2)$, studies $=6, \mathrm{n}=2990$ & 27 & 29 \\
\hline Renal insufficiency (\%), studies $=5, n=5806$ & 10 & 7 \\
\hline$\beta$-Blocker (\%), studies $=4, n=3794$ & 77 & 77 \\
\hline Angiotensin-converting enzyme (ACE) inhibitors (\%), studies $=3, n=1448$ & 53 & 39 \\
\hline Lipid lowering drugs (\%), studies $=4, n=3794$ & 67 & 41 \\
\hline
\end{tabular}




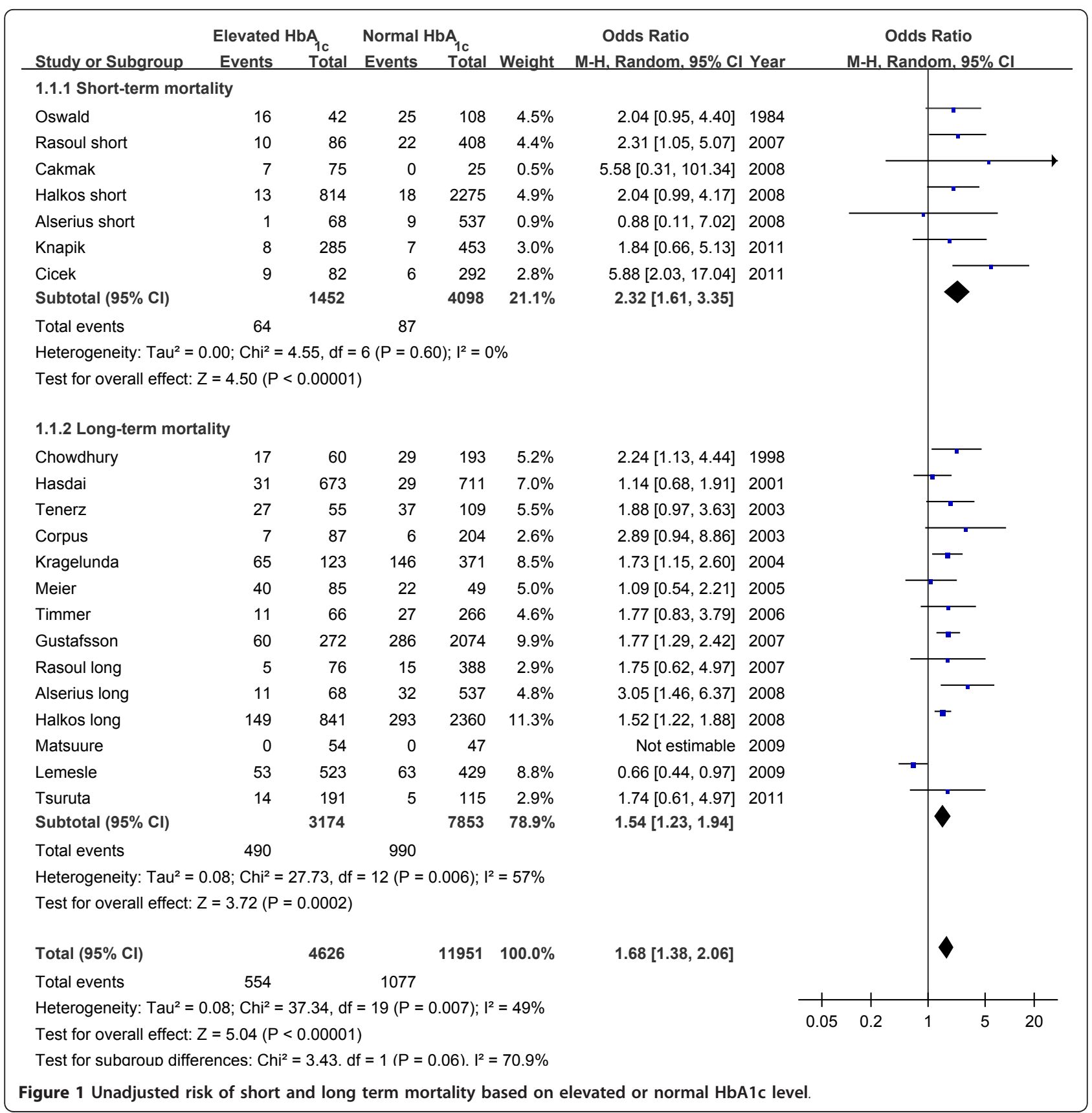

data for diabetic and non- diabetic patients were reported $[13,15,16,18,21-23,28,32,33,35,36]$ (Figure 2). In patients without diabetes, elevated $\mathrm{HbA1c}$ was associated with a $84 \%$ increased risk of mortality (OR 1.84, 95\% CI, 1.51 to 2.24). While in patients with diabetes, elevated HbA1c level was not associated with a significantly higher risk of mortality (OR 0.95, 95\% CI, 0.70 to 1.28).

\section{Risk adjusted analyses}

Eight studies used a Cox proportional hazards regression model to adjust for other prognostic factors to determine independent association of HbA1c with mortality [14,15,20-23,34,35] (Figure 3). All studies adjusted for age and gender. Other covariates adjusted for included diabetes $[14,20,23]$, hypertension $[14,15,22,23]$, hyperlipidemia [14,20,22,33], heart failure [14,15,22,23], smoker [14,15,22,23,35], arrhythmia [22,23], previous CAD [14,15,20,22], multivessel disease [15,20,21], renal function [22,23,35], peripheral vascular disease [23], and study treatment [22]. In patients without diabetes, the pooled analyses suggested elevated HbA1c was independently associated with mortality after multivariate 


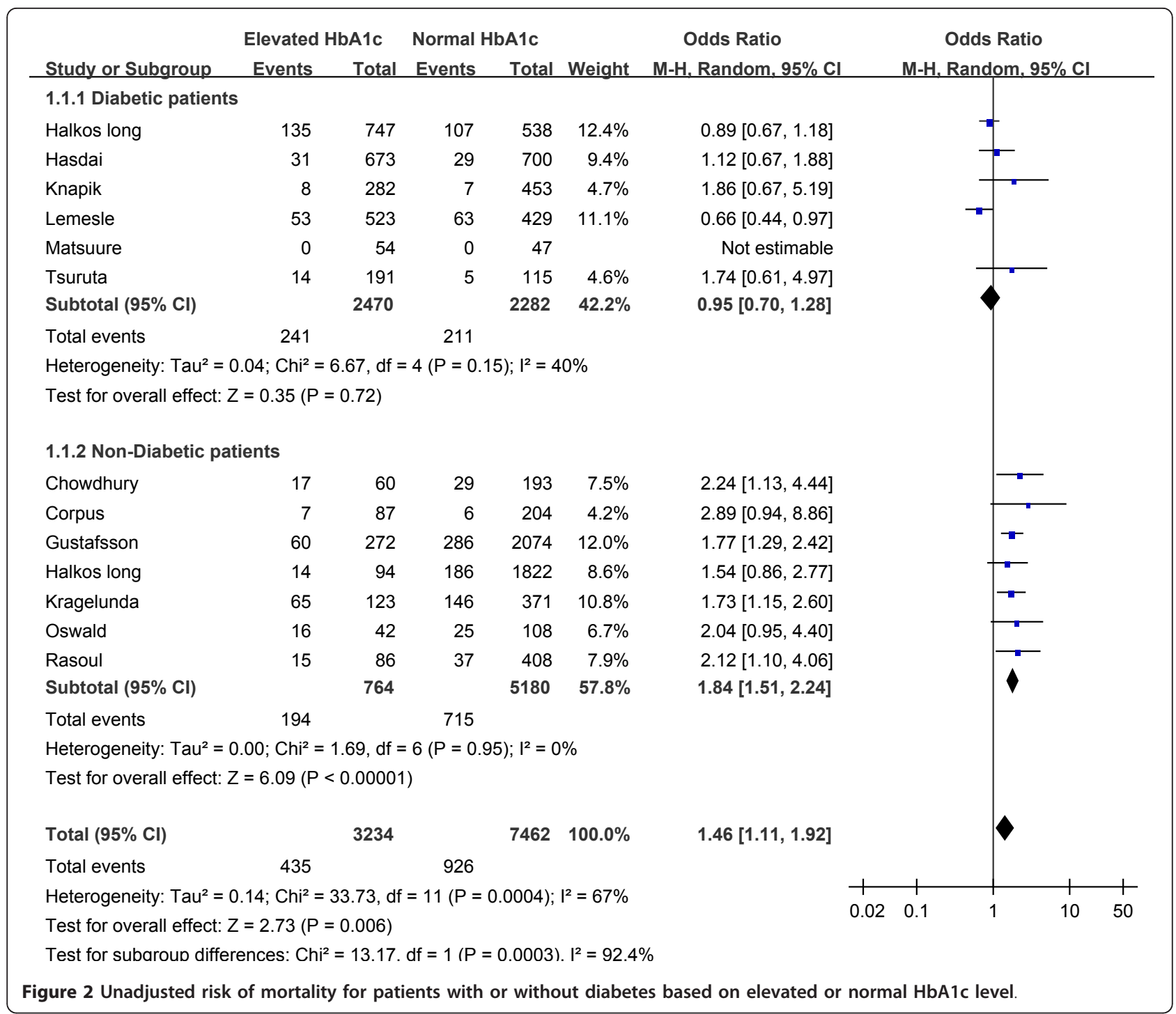

adjusted (adjusted OR 1.24, 95\% CI, 1.01 to 1.54). In the three studies combined data for diabetic and nondiabetic patients, HbA1c level was also a predictor of mortality independent of other prognostic factors (adjusted OR $1.16,95 \%$ CI, 1.03 to 1.30 ). But elevated HbA1c was not significantly associated with adjusted risk of death in diabetic patients (adjusted OR 1.05, 95\% CI, 1.00 to 1.11). The overall pooled adjusted relative risk for elevated $\mathrm{HbA1c}$ was OR, 1.10 (95\% CI, 1.03 to 1.17) for all the eight studies.

\section{Discussion}

The results of our meta-analysis suggest that elevated HbA1c levels predict increased risk of short and long term mortality in patients hospitalized with CAD. Subgroup analyses showed that the impact of HbA1c on mortality seemed to be different between patients with and without diabetes. Elevated HbA1c was associated with a higher risk of mortality in patients without recognized diabetes even after adjusting for other known risk factors, but had a neutral effect on mortality in patients with diabetes.

Diabetes mellitus and acute glycemic control (admission, fasting or preoperative glucose level) are independent prognostic factors for survival following ACS or AMI [1-5,37,38]. Although acute hyperglycemia for most patients may be a manifestation of antecedent disturbed glucose metabolism [1,2], it is also partly caused by the transient stress with release of catecholamines and cortisol $[39,40]$. The adverse outcomes associated with acute hyperglycemia may be somewhat attributed to the stress response to a severe disease state. HbA1c level is a stable indicator of unstressed long-term glucose control and is more useful to predict the abnormal 


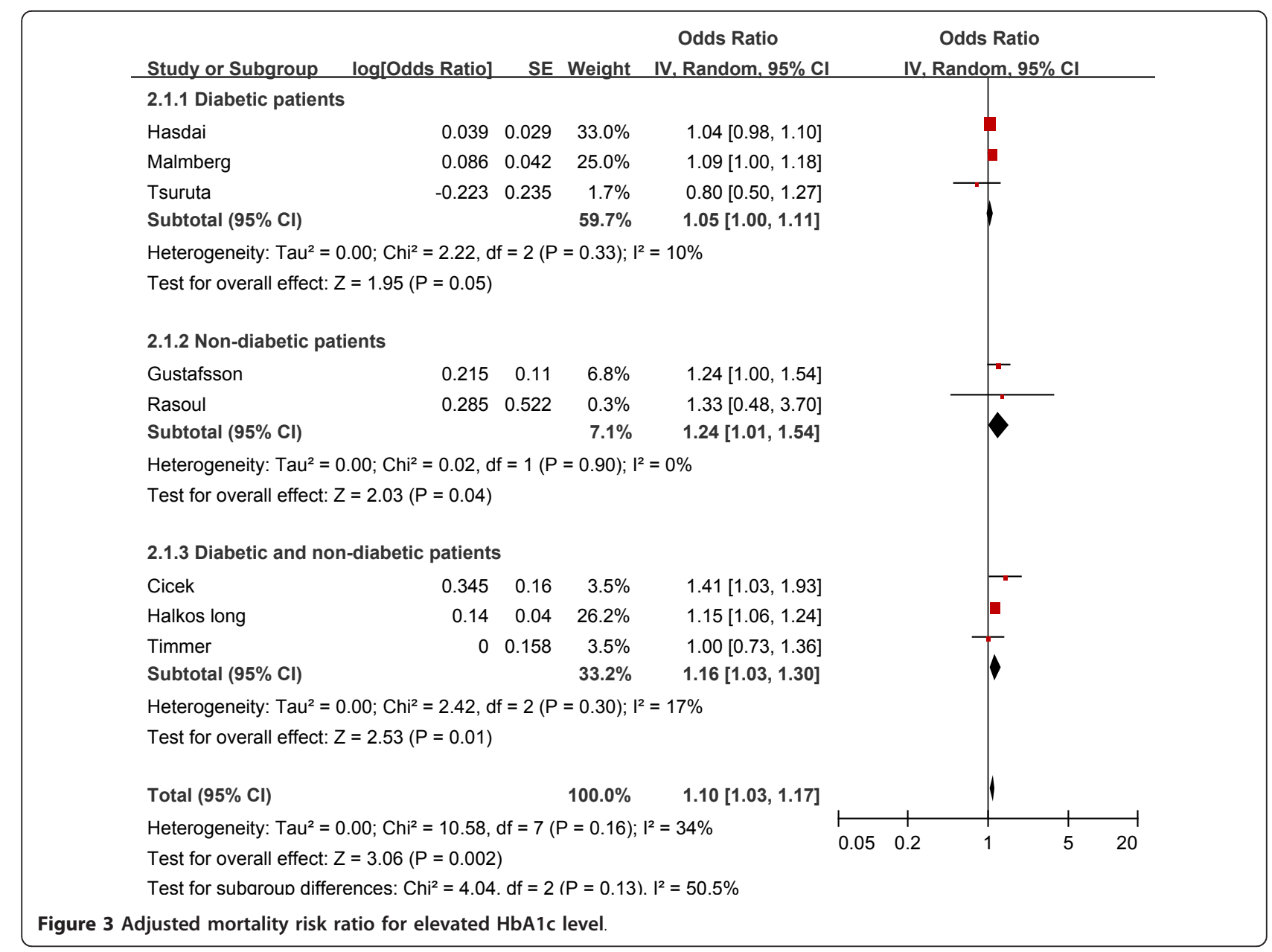

glucose tolerance in CAD patients compared with admission glucose [41]. However, recent studies that evaluated the prognostic value of HbA1c in patients hospitalized with advanced atherosclerosis have reported discrepant results. Several studies showed that although crude mortality data was higher in patients with elevated HbA1c following adjustment for many cardiovascular risk factors, HbA1c values failed to predict mortality independently $[11,15,16,20,30,36]$. Others suggested that HbA1c level was a potent predictor of in-hospital and long-term death $[13,14,21,23,29,31,34]$. After systematically reviewing previous published data and directly comparing the effect of HbA1 on outcomes in patients with and without recognized diabetes, we found that HbA1c levels had different prognostic effects based on patient's diabetes status.

There are several reasons for the discrepant findings between patients with and without diabetes. First, patients with elevated HbA1c but without known diabetes likely have diabetes that was neither diagnosed nor treated, and other relevant cardiovascular risk factors such as hypertension and dyslipidemia that were also untreated before hospitalization; while those with diabetes are more likely to be treated with insulin and control the established risk factors [2,4]. This therapeutic difference may account in part for the disparity in outcomes. Second, the same cutoff value that defined elevated HbA1c may have been relatively too low to distinguish those with chronic hyperglycemia in diabetic patients compared with in non-diabetic patients. Third, recent studies suggested progress in the reperfusion treatment of patients with AMI improved the outcome of diabetic patients [42]. Effective reperfusion especially PCI might attenuate the adverse effect of elevated HbA1c on outcomes of diabetic patients [15]. Fourth, HbA1c may lose its predictive power in diabetic patients with heart failure as it has been recognized for other cardiovascular risk factors like BMI and total cholesterol [43]. A recent study reported the association between mortality and $\mathrm{HbA} 1 \mathrm{C}$ among 5815 diabetic patients with heart failure appeared U-shaped, HbA1c $\leq 7.1$ and $>7.8 \%$ all associated with higher risk of death [44]. Another cohort study in diabetic patients with advanced heart failure observed an inverse relationship between 
HbA1c and long-term mortality [45]. Heart failure was present in $\sim 20 \%$ of the diabetic patients included in our analysis. Future studies should investigate the impact of HbA1c in different high-risk diabetic populations with CAD. Fifth, the UK Prospective Diabetes Study (UKPDS) showed that although intensive glycemic treatment resulted in a non-significant improvement in macrovascular disease during the 5-year trial period [46], the 10-year follow-up demonstrated a significant risk reduction for myocardial infarction and death emerged over time [47]. The follow-up periods for diabetic patients in our study were all less than five years. Therefore, if the follow-up periods were longer, more differences in the mortality between diabetic patients with and without elevated HbA1c might have emerged.

Elevated HbA1c level is likely the result of long term insulin resistance; metabolic disturbances associated with insulin resistance including hyperglycemia, dyslipidemia, hypercoagulability and inflammation might the major pathologic mechanism for the adverse impact of elevated $\mathrm{HbA} 1 \mathrm{c}$ in the setting of CAD [48]. In riskadjusted analysis, after adjusted for other prognostic factors such as old age, hypertension, prior myocardial infarction, and hyperlipidaemia, HbA1c remained independently associated with increased mortality risk (except for patients with diabetes), but it was observed that the associations were attenuated. This suggested that the adverse effect of HbA1c on mortality is somewhat attributable to a correlation with other cardiovascular risk factors. The presence of an elevated HbA1c level, through its association with the metabolic syndrome, may potentially predate the development of other risk factors, and hence these risk factors may represent a common biological proatherogenic pathway $[49,50]$.

Prior clinical trials of intensive glucose control have shown little benefit, and possibly some harm, of lowering the $\mathrm{HbA1c}$ level in patients with diabetes to prevent cardiovascular outcomes $[46,47,51,52]$. The results of two recent meta-analyses suggested that intensive glucose control reduced cardiovascular events with no effect on mortality [53,54], and subgroup analyses showed participants with a history of cardiovascular disease did not appear to benefit from intensive therapy [54]. The majority of current trials for glycemic control were designed primarily to patients with established diabetes. Our observation support the need for large randomized trials designed to confirm or refute preliminary suggestions that intensive glycemic control may improve outcomes in CAD patients without diabetes and elevated HbA1c level.

Several limitations of this meta-analysis should be noted. First, the pooled studies differed in inclusion and exclusion criteria, cutoffs for elevated HbA1c, definition of diabetes, duration of follow-up and concomitant treatment. These may be the major source of heterogeneity. We used a random effects model in an effort to incorporate heterogeneity between trials in our analysis, but recognize that this does not eliminate the fact that heterogeneities were present. Second, given the lack of data in some studies, less than half the studies were combined for adjusted analysis, which meant that the results of risk-adjusted analysis were less conclusive. And the covariates adjusted in each study were different. Given the limitations, the results should be interpreted cautiously. Third, although we found no significant effect of elevated HbA1c on all-cause mortality in patients with diabetes, recent studies suggested that HbA1c was associated with an increased risk of major adverse cardiac events following stent implantation [55] and was a predictor of ischemic events in diabetic patients [56]. The prognostic effect of HbA1c on other cardiovascular events in diabetic patients with CAD needs further evaluation. Finally, given that a proportion of studies included are retrospective, a possibility of residual confounding by unmeasured factors cannot be eliminated. This provided associative, not causal, evidence and mandates caution when interpreting these results.

\section{Conclusions}

In conclusion, we found that $\mathrm{HbA} 1 \mathrm{c}$ level is an independent predictor of total mortality in CAD patients without but not in patients with established diabetes. Glycemic control, diabetes screening, and risk factor modification may represent opportunities to improve care in this group of patients.

\section{Additional material}

Additional file 1: Characteristics of selected studies. Additional file shows baseline characteristics of the 20 studies included.

\section{Acknowledgements}

We thank Juris J. Meier and Michael A. Nauck for their unpublished data that were included in this analysis.

\section{Authors' contributions}

YL and YMY contributed to study concept and design, search of the literatures, data extraction, data analyses, and the drafting and review of the final manuscript. JZ contributed to the conception and design of the analysis, interpreted the analyzed data, critically reviewed the manuscript, and helped to draft the manuscript. HQT, YL, and JDL participated in design of the analysis, data interpretation, and review of the manuscript. All authors read and approved the final manuscript.

\section{Competing interests}

The authors declare that they have no competing interests.

Received: 8 August 2011 Accepted: 10 November 2011 Published: 10 November 2011 


\section{References}

1. Kosiborod M, Rathore SS, Inzucchi SE, Masoudi FA, Wang Y, Havranek EP, Krumholz HM: Admission glucose and mortality in elderly patients hospitalized with acute myocardial infarction: implications for patients with and without recognized diabetes. Circulation 2005, 111:3078-3086.

2. Deedwania P, Kosiborod M, Barrett E, Ceriello A, Isley W, Mazzone T, Raskin P, American Heart Association Diabetes Committee of the Council on Nutrition, Physical Activity, and Metabolis: Hyperglycemia and acute coronary syndrome: a scientific statement from the American Heart Association Diabetes Committee of the Council on Nutrition, Physical Activity, and Metabolism. Circulation 2008, 117:1610-9.

3. Suleiman M, Hammerman $H$, Boulos M, Kapeliovich MR, Suleiman A, Agmon Y, Markiewicz W, Aronson D: Fasting glucose is an important independent risk factor for 30-day mortality in patients with acute myocardial infarction: a prospective study. Circulation 2005, 111:754-760.

4. Straumann E, Kurz DJ, Muntwyler J, Stettler I, Furrer M, Naegeli B, Frielingsdorf J, Schuiki E, Mury R, Bertel O, Spinas GA: Admission glucose concentrations independently predict early and late mortality in patients with acute myocardial infarction treated by primary or rescue percutaneous coronary intervention. Am Heart J 2005, 150:1000-6.

5. Imran SA, Ransom TP, Buth KJ, Clayton D, Al-Shehri B, Ur E, Ali IS: Impact of admission serum glucose level on in-hospital outcomes following coronary artery bypass grafting surgery. Can J Cardiol 2010, 26:151-4.

6. Stratton IM, Adler Al, Neil HA, Matthews DR, Manley SE, Cull CA, Hadden D, Turner RC, Holman RR: Association of glycaemia with macrovascular and microvascular complications of type 2 diabetes (UKPDS 35): prospective observational study. BMJ 2000, 321:405-12.

7. Selvin E, Steffes MW, Zhu H, Matsushita K, Wagenknecht L, Pankow J, Coresh J, Brancati FL: Glycated hemoglobin, diabetes, and cardiovascular risk in nondiabetic adults. N Engl J Med 2010, 362:800-11.

8. Eeg-Olofsson K, Cederholm J, Nilsson PM, Zethelius B, Svensson AM, Gudbjörnsdóttir S, Eliasson B: New aspects of $\mathrm{HbA1c}$ as a risk factor for cardiovascular diseases in type 2 diabetes: an observational study from the Swedish National Diabetes Register (NDR). J Intern Med 2010, 268:471-82.

9. Nishimura R, Nakagami T, Sone H, Ohashi Y, Tajima N: Relationship between hemoglobin A1C and cardiovascular disease in mild-tomoderate hypercholesterolemic Japanese individuals: subanalysis of a large-scale randomized controlled trial. Cardiovasc Diabetol 2011, 10:58.

10. The International Expert Committee: International Expert Committee Report on the role of the A1C assay in the diagnosis of diabetes. Diabetes Care 200, 32:1327-1334.

11. Hadjadj S, Coisne D, Mauco G, Ragot S, Duengler F, Sosner P, Torremocha F, Herpin D, Marechaud R: Prognostic value of admission plasma glucose and $\mathrm{HbA}$ in acute myocardial infarction. Diabet Med 2004, 21:305-310.

12. Cao JJ, Hudson M, Jankowski M, Whitehouse F, Weaver WD: Relation of chronic and acute glycemic control on mortality in acute myocardial infarction with diabetes mellitus. Am J Cardio/ 2005, 96:183-186.

13. Chowdhury TA, Lasker SS: Elevated glycated haemoglobin in non-diabetic patients is associated with an increased mortality in myocardial infarction. Postgrad Med J 1998, 74:480-1.

14. Malmberg K, Norhammar A, Wedel H, Rydén L: Glycometabolic state at admission: important risk marker of mortality in conventionally treated patients with diabetes mellitus and acute myocardial infarction: longterm results from the Diabetes and Insulin-Glucose Infusion in Acute Myocardial Infarction (DIGAMI) study. Circulation 1999, 99:2626-32.

15. Hasdai D, Rizza RA, Grill DE, Scott CG, Garratt KN, Holmes DR Jr: Glycemic control and outcome of diabetic patients after successful percutaneous coronary revascularization. Am Heart J 2001, 141:117-23.

16. Corpus RA, O'Neill WW, Dixon SR, Timmis GC, Devlin WH: Relation of hemoglobin A1c to rate of major adverse cardiac events in nondiabetic patients undergoing percutaneous coronary revascularization. Am Cardiol 2003, 92:1282-6.

17. Tenerz A, Nilsson G, Forberg R, Ohrvik J, Malmberg K, Berne C, Leppert J: Basal glucometabolic status has an impact on long-term prognosis following an acute myocardial infarction in non-diabetic patients. Intern Med 2003, 254:494-503.

18. Kragelund C, Snorgaard O, Køber L, Bengtsson B, Ottesen M, Højberg S, Olesen C, Kjaergaard JJ, Carlsen J, Torp-Petersen C, TRACE Study Group: Hyperinsulinaemia is associated with increased long-term mortality following acute myocardial infarction in non-diabetic patients. Eur Heart J 2004, 25:1891-7.

19. Meier JJ, Deifuss S, Klamann A, Launhardt V, Schmiegel WH, Nauck MA: Plasma glucose at hospital admission and previous metabolic control determine myocardial infarct size and survival in patients with and without type 2 diabetes: the Langendreer Myocardial Infarction and Blood Glucose in Diabetic Patients Assessment (LAMBDA). Diabetes Care 2005, 28:2551-3

20. Timmer JR, Ottervanger JP, Bilo HJ, Dambrink JH, Miedema K, Hoorntje JC Zijlstra F: Prognostic value of admission glucose and glycosylated haemoglobin levels in acute coronary syndromes. QJM 2006, 99:237-43.

21. Rasoul S, Ottervanger JP, Bilo HJ, Timmer JR, van 't Hof AW, Dambrink JH, Dikkeschei LD, Hoorntje JC, de Boer MJ, Zijlstra F: Glucose dysregulation in nondiabetic patients with ST-elevation myocardial infarction: acute and chronic glucose dysregulation in STEMI. Neth J Med 2007, 65:95-100.

22. Gustafsson I, Kistorp CN, James MK, Faber JO, Dickstein K, Hildebrandt PR, OPTIMAAL Study Group: Unrecognized glycometabolic disturbance as measured by hemoglobin A1C is associated with a poor outcome after acute myocardial infarction. Am Heart J 2007, 154:470-6.

23. Halkos ME, Lattouf OM, Puskas JD, Kilgo P, Cooper WA, Morris CD Guyton RA, Thourani VH: Elevated preoperative hemoglobin A1c level is associated with reduced long-term survival after coronary artery bypass surgery. Ann Thorac Surg 2008, 86:1431-7.

24. Stroup DF, Berlin JA, Morton SC, Olkin I, Williamson GD, Rennie D, Moher D, Becker BJ, Sipe TA, Thacker SB: Meta-analysis of observational studies in epidemiology: a proposal for reporting: Meta-Analysis of Observational Studies in Epidemiology (MOOSE) group. JAMA 2000, 283:2008-2012.

25. American Diabetes Association. Standards of medical care in diabetes. Diabetes Care 2005, 28(Suppl 1):S4-S36.

26. Harris RP, Helfand M, Woolf SH, Lohr KN, Mulrow CD, Teutsch SM, Atkins D, Methods Work Group, Third US Preventive Services Task Force: Current methods of the US Preventive Services Task Force: a review of the process. Am J Prev Med 2001, 20:21-35.

27. Altman DG: Systematic reviews of evaluations of prognostic variables. BMJ 2001, 323:224-8

28. Oswald GA, Corcoran S, Yudkin JS: Prevalence and risks of hyperglycaemia and undiagnosed diabetes in patients with acute myocardial infarction. Lancet 1984, 1:1264-7.

29. Halkos ME, Puskas JD, Lattouf OM, Kilgo P, Kerendi F, Song HK, Guyton RA, Thourani VH: Elevated preoperative hemoglobin A1c level is predictive of adverse events after coronary artery bypass surgery. J Thorac Cardiovasc Surg 2008, 136:631-40.

30. Cakmak M, Cakmak N, Cetemen S, Tanriverdi H, Enc Y, Teskin O, Kilic ID: The value of admission glycosylated hemoglobin level in patients with acute myocardial infarction. Can J Cardiol 2008, 24:375-8.

31. Alserius $T$, Anderson RE, Hammar N, Nordqvist T, Ivert T: Elevated glycosylated haemoglobin $(\mathrm{HbA} 1 \mathrm{c})$ is a risk marker in coronary artery bypass surgery. Scand Cardiovasc J 2008, 42:392-8.

32. Matsuura K, Imamaki M, Ishida A, Shimura H, Niitsuma Y, Miyazaki M: Offpump coronary artery bypass grafting for poorly controlled diabetic patients. Ann Thorac Cardiovasc Surg 2009, 15:18-22.

33. Lemesle G, Bonello L, de Labriolle A, Maluenda G, Syed Al, Collins SD, BenDor I, Torguson R, Kaneshige K, Xue Z, Suddath WO, Satler LF, Kent KM, Lindsay J, Pichard AD, Waksman R: Prognostic value of hemoglobin A1C levels in patients with diabetes mellitus undergoing percutaneous coronary intervention with stent implantation. Am J Cardiol 2009, 104:41-5.

34. Cicek G, Uyarel H, Ergelen M, Ayhan E, Abanonu GB, Eren M, Gibson CM: Hemoglobin $\mathrm{A} 1 \mathrm{C}$ as a prognostic marker in patients undergoing primary angioplasty for acute myocardial infarction. Coron Artery Dis 2011, 22:131-7.

35. Tsuruta R, Miyauchi K, Yamamoto T, Dohi S, Tambara K, Dohi T, Inaba H, Kuwaki K, Daida H, Amano A: Effect of preoperative hemoglobin A1c levels on long-term outcomes for diabetic patients after off-pump coronary artery bypass grafting. J Cardiol 2011, 57:181-6.

36. Knapik P, Cieśla D, Filipiak K, Knapik M, Zembala M: Prevalence and clinical significance of elevated preoperative glycosylated hemoglobin in diabetic patients scheduled for coronary artery surgery. Eur J Cardiothorac Surg 2011, 39:484-9. 
37. Donahoe SM, Stewart GC, MCCabe CH, Mohanavelu S, Murphy SA Cannon CP, Antman EM: Diabetes and mortality following acute coronary syndromes. JAMA 2007, 298:765-75.

38. Kümler T, Gislason GH, Køber L, Torp-Pedersen C: Diabetes is an independent predictor of survival 17 years after myocardial infarction: follow-up of the TRACE registry. Cardiovasc Diabetol 2010, 9:22.

39. Husband DJ, Alberti KG, Julian DG: 'Stress'hyperglycaemia during acute myocardial infarction: an indicator of pre-existing diabetes? Lancet 1983, ii:179-181.

40. Monnier L, Mas E, Ginet C, Michel F, Villon L, Cristol JP, Colette C: Activation of oxidative stress by acute glucose fluctuations compared with sustained chronic hyperglycemia in patients with type 2 diabetes. JAMA 2006, 295:1681-1687.

41. Ishihara M, Inoue I, Kawagoe T, Shimatani Y, Kurisu S, Hata T, Nakama Y, Kijima Y, Kagawa E: Is admission hyperglycaemia in non-diabetic patients with acute myocardial infarction a surrogate for previously undiagnosed abnormal glucose tolerance? Eur Heart J 2006, 27:2413-9.

42. Hadjadj S, Coisne D, Mauco G, Ragot S, Duengler F, Sosner P, Torremocha F, Herpin D, Marechaud R: Diabetes mellitus and outcome after primary coronary angioplasty for acute myocardial infarction: lessons from the GUSTO-IIb angioplasty substudy. J Am Coll Cardiol 2000, 35:1502-1512.

43. Gustafsson F, Kragelund CB, Torp-Pedersen C: Effect of obesity and being overweight on long-term mortality in congestive heart failure: influence of left ventricular systolic function. Eur Heart J 2005, 26:58-64.

44. Aguilar D, Bozkurt B, Ramasubbu K, Deswal A: Relationship of hemoglobin $\mathrm{A} 1 \mathrm{C}$ and mortality in heart failure patients with diabetes. J Am Coll Cardiol 2009, 54:422-8.

45. Eshaghian S, Horwich TB, Fonarow GC: An unexpected inverse relationship between $\mathrm{HbA} 1 \mathrm{c}$ levels and mortality in patients with diabetes and advanced systolic heart failure. Am Heart J 2006, 151:91. e1-91.e6.

46. UK Prospective Diabetes Study (UKPDS) Group: Intensive blood-glucose control with sulphonylureas or insulin compared with conventional treatment and risk of complications in patientswith type 2 diabetes (UKPDS 33). Lancet 1998, 352:837-853.

47. Holman RR, Paul SK, Bethel MA, Neil HA, Matthews DR: Long-term followup after tight control of blood pressure in type 2 diabetes. N Engl I Med 2008, 359:1565-76

48. Bansilal S, Farkouh ME, Fuster V: Role of insulin resistance and hyperglycemia in the development of atherosclerosis. Am J Cardiol 2007, 99:6B-14B.

49. DeFronzo RA, Ferrannini E: Insulin resistance: a multifaceted syndrome responsible for NIDDM, obesity, hypertension, dyslipidemia, and atherosclerotic cardiovascular disease. Diabetes Care 1991, 14:173-194.

50. Grundy SM: Obesity, metabolic syndrome, and coronary atherosclerosis. Circulation 2002, 105:2696-2698.

51. Duckworth W, Abraira C, Moritz T, Reda D, Emanuele N, Reaven PD, Zieve FJ, Marks J, Davis SN, Hayward R, Warren SR, Goldman S, McCarren M, Vitek ME, Henderson WG, Huang GD, VADT Investigators: Glucose control and vascular complications in veterans with type 2 diabetes. $N$ Engl J Med 2009, 360:129-139.

52. Action to Control Cardiovascular Risk in Diabetes Study Group, Gerstein HC, Miller ME, Byington RP, Goff DC Jr, Bigger JT, Buse JB, Cushman WC, Genuth S, Ismail-Beigi F, Grimm RH Jr, Probstfield JL, Simons-Morton DG, Friedewald WT: Effects of intensive glucose lowering in type 2 diabetes. N Engl J Med 2008, 358:2545-59.

53. Ray KK, Seshasai SR, Wijesuriya S, Sivakumaran R, Nethercott S, Preiss D, Erqou S, Sattar N: Effect of intensive control of glucose on cardiovascular outcomes and death in patients with diabetes mellitus: a meta-analysis of randomised controlled trials. Lancet 2009, 373:1765-72.

54. Control Group, Turnbull FM, Abraira C, Anderson RJ, Byington RP, Chalmers JP, Duckworth WC, Evans GW, Gerstein HC, Holman RR, Moritz TE, Neal BC, Ninomiya T, Patel AA, Paul SK, Travert F, Woodward M: Intensive glucose control and macrovascular outcomes in type 2 diabetes. Diabetologia 2009, 52:2288-98.

55. Ueda H, Mitsusada N, Harimoto K, Miyawaki M, Yasuga Y, Hiraoka H: Glycosylated hemoglobin is a predictor of major adverse cardiac events after drug-eluting stent implantation in patients with diabetes mellitus. Cardiology 2010, 116:51-7.
56. Camafort M, Alvarez-Rodríguez LR, Muñoz-Torrero JF, Sahuquillo JC, LópezJiménez L, Coll R, Monreal M, FRENA Investigators: Glucose control and outcome in patients with stable diabetes and previous coronary, cerebrovascular or peripheral artery disease. Findings from the FRENA Registry. Diabet Med 2011, 28:73-80.

doi:10.1186/1475-2840-10-98

Cite this article as: Liu et al:. Prognostic significance of hemoglobin A1c level in patients hospitalized with coronary artery disease. A systematic review and meta-analysis. Cardiovascular Diabetology 2011 10:98.

\section{Submit your next manuscript to BioMed Central and take full advantage of:}

- Convenient online submission

- Thorough peer review

- No space constraints or color figure charges

- Immediate publication on acceptance

- Inclusion in PubMed, CAS, Scopus and Google Scholar

- Research which is freely available for redistribution 